\title{
Convivência Harmônica Entre Linhagens de Leveduras Killer e Sensíveis
}

Sheila Canossa (II), Bruna Agustini (I), Gildo Almeida da Silva (I)

(I) CNPUV - Embrapa Uva e Vinho (Rua Livramento 515, CEP:95700000, Bento Gonçalves-

RS), (II) UFRGS - Universidade Federal do Rio Grande do Sul (Avenida Bento Gonçalves, 9500,CEP 91501-970 Porto Alegre, RS)

\section{Resumo}

Sabe-se que algumas leveduras podem liberar glicoproteínas, conhecidas como fator killer, que matam linhagens sensíveis. Em relação ao fator killer, as leveduras são classificadas como sensível (K- R-), killer (K+R+) e neutras (K- R+). A capacidade killer das linhagens de Saccharomyces cerevisiae é determinada por partículas citoplasmáticas semelhantes a vírus (VLP). Estas partículas são compostas por segmentos lineares de RNA de cadeia dupla. As linhagens killer possuem VLPs de diferentes tamanhos sendo M-dsRNA (médio) e L-dsRNA (grande). Para que uma linhagem apresente comportamento killer é necessário que esta possua a VLP MdsRNA. O objetivo deste trabalho foi avaliar a resposta killer de 34 linhagens isoladas da cultivar Merlot da região de Pinto Bandeira com relação às linhagens killer $7 \mathrm{M}, 12 \mathrm{M}, 24 \mathrm{M}, 25 \mathrm{M}$ e $30 \mathrm{M}$, isoladas da mesma localidade, tendo-se como padrão killer as linhagens de referência da espécie Saccharomyces cerevisiae, denominadas Embrapa 1B, Embrapa 91B e uma linhagem comercial K1 (Lallemand). As linhagens teste foram $1 \mathrm{M}, 2 \mathrm{M}, 4 \mathrm{M} 5 \mathrm{M}, 6 \mathrm{M}, 7 \mathrm{M}, 8 \mathrm{M}, 9 \mathrm{M}, 10 \mathrm{M}, 11 \mathrm{M}, 12 \mathrm{M}, 14 \mathrm{M}, 15 \mathrm{M}, 16 \mathrm{M}$, $17 \mathrm{M}, 18 \mathrm{M}, 20 \mathrm{M}, 21 \mathrm{M}, 22 \mathrm{M}, 24 \mathrm{M}, 25 \mathrm{M}, 26 \mathrm{M}, 27 \mathrm{M}, 29 \mathrm{M}, 30 \mathrm{M}, 31 \mathrm{M}$, $32 \mathrm{M}, 33 \mathrm{M}, 34 \mathrm{M}, 35 \mathrm{M}, 36 \mathrm{M}, 37 \mathrm{M}, 38 \mathrm{M}, 39 \mathrm{M}$ e 40M. Os experimentos foram conduzidos em meio mosto Lorena/ELNC (80:20) $\mathrm{pH} 4,5$. As linhagens testadas foram plaqueadas sobre o meio e massas pontuais das oito linhagens killer foram aplicadas em triplicata sob o meio. As placas foram acondicionadas em estufa à $24^{\circ} \mathrm{C}$ de 48 a 72 horas. Os resultados mostraram que as linhagens $10 \mathrm{M}$ e $29 \mathrm{M}$ apresentaram sensibilidade à 
proteína killer das linhagens $12 \mathrm{M}$ e 30M. A linhagem 20M foi sensível apenas à linhagem 12M. As linhagens referência K1 e 91B também apresentaram sensibilidade à proteína killer das leveduras $12 \mathrm{M}$ e $30 \mathrm{M}$. Entretanto, as linhagens $10 \mathrm{M}, 20 \mathrm{M}$ e $29 \mathrm{M}$ não apresentaram sensibilidade ao fator killer das linhagens killer de referência K1, 91B e 1B. A frequência de linhagens killer, sensível e neutra depende do ambiente de onde foram isoladas e especialmente das linhagens de referência empregadas. $\mathrm{O}$ fato de se isolar linhagens killer, sensíveis e neutras de um mesmo ambiente sugere haver na natureza mecanismos que possibilitem a convivência harmônica entre linhagens killer e sensíveis. É possível que um destes mecanismos esteja relacionado com a presença simultânea de linhagens neutras num mesmo micro-habitat.

Palavras-Chave: Killer, sensível, leveduras Agência de Fomento: CAPES, FAPERGS 